\title{
PERENCANAAN MANAJEMEN PROYEK JARINGAN KOMPUTER PADA PT LOVALATTES INDONESIA
}

\author{
Nurhayati ${ }^{1}$,Bidara Kadija ${ }^{1}$,Teguh gumilang ${ }^{3}$, Husain Faiz Karimi ${ }^{4}$ \\ 1,2,3,4 Teknik Informatika, Fakultas Sains dan Teknologi \\ UIN Syarif Hidayatullah Jakarta \\ nurhayati@uinjkt.ac.id, bidarakadija28,gteguh25, husainpais1(@ gmail.com
}

\begin{abstract}
ABSTRAK
Seiring dengan perkembangan zaman dan teknologi informasi, serta kebutuhan manusia terhadap suatu permasalahan pekerjaan yang tinggi menuntut peran sebuah teknologi untuk menjawab semua permasalahan tersebut. Electronic Commerce (E-Commerce) didefinisikan sebagai proses pembelian dan penjualan produk, jasa dan informasi yang dilakukan secara elektronik dengan memanfaatkan jaringan komputer. Salah satu jaringan yang digunakan adalah internet. Dengan menghubungkan jaringan komputer perusahaan dengan internet, perusahaan dapat menjalin hubungan bisnis dengan rekan bisnis atau konsumen secara lebih efisien. Penggunaan E-Commerce dapat meningkatkan efisiensi biaya dan produktifitas perusahaan, sehingga dapat meningkatkan kemampuan perusahaan dalam bersaing.
\end{abstract}

Kata Kunci:e-commerce, Manajemen proyek, Infrastruktur jaringan

\begin{abstract}
Along with the times and information technology, and human needs to a problem that high job demands the role of a technology to address all these problems. Electronic Commerce (ECommerce) is defined as the process of buying and selling of products, services and information that will be conducted electronically by using computer networks. One of the network used is the Internet. By connecting the company's network to the Internet, companies can establish business relationships with business partners or customers more efficiently. Use of E-Commerce can improve cost efficiency and productivity of the company, so as to enhance the company's ability to compete.
\end{abstract}

Key words: e-commerce, project management, network infrastructure 


\section{PENDAHULUAN}

Teknologi dan komunikasi dewasa ini telah berkembang dengan cepat dan selaras dengan perkembangan karakteristik masyarakat modern yang memiliki mobilitas tinggi, mencari layanan yang fleksibel, serba mudah, dan mengejar efisiensi di segala bidang, sehingga kebutuhan akan informasi dan komunikasi pun meningkat.

Seiring dengan perkembangan zaman dan teknologi informasi, serta kebutuhan manusia terhadap suatu permasalahan pekerjaan yang tinggi menuntut peran sebuah teknologi untuk menjawab semua permasalahan tersebut. Untuk mendukung teknologi dalam pengiriman informasi maka dibutuhkan teknologi telekomunikasi dalam mengkomunikasikan antar komputer satu dengan yang lainnya. Adapun teknologi telekomunikasi tersebut adalah jaringan komputer.

Penggabungan teknologi informasi dan telekomunikasi sangat berpengaruh terhadap sistem komputer sehingga terjadi pergeseran dari komputer terpusat menjadi jaringan komputer dimana tugas-tugas komputasi ditangani oleh banyak komputer yang terpisahpisah tetapi dapat saling berkomunikasi melaksanaan tugas-tugas tersebut.

Electronic Commerce (E-Commerce) didefinisikan sebagai proses pembelian dan penjualan produk, jasa dan informasi yang dilakukan secara elektronik dengan memanfaatkan jaringan komputer. Salah satu jaringan yang digunakan adalah internet. Perkembangan teknologi informasi terutama internet, merupakan faktor pendorong perkembangan e-commerce. Internet merupakan jaringan global yang menyatukan jaringan komputer di seluruh dunia, sehingga memungkinkan terjalinnya komunikasi dan interaksi antara satu dengan yang lain diseluruh dunia. Dengan menghubungkan jaringan komputer perusahaan dengan internet, perusahaan dapat menjalin hubungan bisnis dengan rekan bisnis atau konsumen secara lebih efisien. Sampai saat ini internet merupakan infrastruktur yang ideal untuk menjalankan e-commerce, sehingga istilah ECommerce pun menjadi identik dengan menjalankan bisnis di internet.

Pertukaran informasi dalam E-Commerce dilakukan dalam format dijital sehingga kebutuhan akan pengiriman data dalam bentuk cetak dapat dihilangkan. Dengan menggunakan sistem komputer yang saling terhubung melalui jaringan telekomunikasi, transaksi bisnis dapat dilakukan secara otomatis dan dalam waktu yang singkat. Akibatnya informasi yang dibutuhkan untuk keperluan transaksi bisnis tersedia pada saat diperlukan. Dengan melakukan bisnis secara elektronik, perusahaan dapat menekan biaya yang harus dikeluarkan untuk keperluan pengiriman informasi. Proses transaksi yang berlangsung secara cepat juga mengakibatkan meningkatnya produktifitas perusahaan.

Penggunaan E-Commerce dapat meningkatkan efisiensi biaya dan produktifitas perusahaan, sehingga dapat meningkatkan kemampuan perusahaan dalam bersaing.

Oleh karena itu penulis mengajukan suatu usulan dalam perancangan jaringan komputer di PT Lovalattes Indonesia.. Dimana dari perancangan yang diusulkan, dilakukan dalam rangka peningkatan kualitas layanan terhadap konsumen Lovalatte Departement Store.

Demi memberikan kepuasan dan pelayanan terbaik bagi para konsumen, seiring dengan perkembangan teknologi informasi yang cukup pesat, Lovalattes akan merambah dunia ecommerce, dimana para konsumen bisa membeli produk-produk yang Lovalattes yang sediakan secara online.

\section{TINJAUAN PUSTAKA}

\subsection{Jaringan}

Jaringan adalah sekelompok dua / lebih sistem komputer yang dapat memberikan layanan berbagi dan berinteraksi dalam beberapa cara. Interaksi ini, dicapai melaluilink komunikasi data. Sederhananya jaringan adalah kumpulan mesin telah dikaitkan baik secara fisik dan melalui perangkat lunak komponen untuk memfasilitasi komunikasi dan berbagi informasi.

\subsubsection{Topologi Jaringan}

Topologi jaringan adalah tata letak geometris dasar tentang bagaimana klien dan server yang terhubung ke saluran (dan karenanya sama lain). Tiga topologi jaringan umum adalah bintang, bus dan cincin. Topologi dikaitkan dengan akses channel (lihat catatan pada lapisan-2 protokol), karena cara kita menghubungkan komputer ke saluran Membatasi, sampai batas tertentu, bagaimana mereka dapat mengakses saluran. Setiap 
metode akses channel (dan karenanya, setiap lapisan-2 protokol), oleh karena itu, memerlukan topologi tertentu.

\subsubsection{Infrastruktur Jaringan}

Infrastruktur jaringan mengacu pada hardware dan software sumber dari seluruh jaringan yang memungkinkan konektivitas jaringan, komunikasi, operasi dan manajemen dari jaringan perusahaan.

Infrastruktur jaringan menyediakan jalur dan layanan komunikasi antara pengguna, proses, aplikasi, layanan dan jaringan eksternal / Internet.

Infrastruktur jaringan biasanya bagian dari infrastruktur TI ditemukan di sebagian besar lingkungan TI perusahaan. Seluruh infrastruktur jaringan yang saling berhubungan, dan dapat digunakan untuk komunikasi internal, komunikasi eksternal atau keduanya. Sebuah infrastruktur jaringan umum meliputi:

Jaringan Hardware:

- Router

- Switch

- Kartu LAN

- Wireless router

- Kabel

Jaringan Software:

- Operasi jaringan dan manajemen

- Sistem operasi

- Firewall

- Aplikasi keamanan jaringan

Network Services:

- DSL

- Satelit

- Protokol nirkabel

- Pengalaman IP

\subsection{Manajemen Proyek}

Manajemen proyek adalah penerapan pengetahuan, ketrampilan, alat bantu dan teknis-teknis pada aktivitas-aktivitas proyek agar persyaratan dan kebutuhan proyek terpenuhi (Heryanto dan Totok, 2009: 27). Manfaat yang dapat diperoleh dengan adanya manajemen proyek antara lain: a. Efsiensi baik dari sisi biaya, sumber daya maupun waktu.

b. Monitoring dan evaluasi terhadap kemajuan proyek menjadi lebih baik sehingga proyek dapat sesuai dengan scope, biaya, sumber daya dan waktu yang telah ditentukan.

c. Meningkatkan kualitas produk yang dihasilkan.

d. Meningkatkan produktivitas dari masing-masing tim.

e. Dapat meminimalisir risiko yang mungkin terjadi.

f. Kondisi intenal tim proyek yang lebih baik.

g. Meningkatkan semangat, tanggung jawab serta loyalitas tim terhadap proyek dengan memberikan penugasan yang jelas kepada masing-masing anggota tim.

Setiap proyek memiliki tujuan khusus, didalam proses pencapaian tujuan tersebut ada tiga faktor pembatas yang harus dipenuhi yang dikenal dengan Trade-off Triangle atau Triple Constrain (Heryanto dan Totok, 2009:29), yaitu:

a. Lingkup (scope)

Scope atau lingkup proyek membahas jenis dan batasan- batasan yang ada pada sebuah proyek yang menjadi acuan dalam menyusun pekerjaaan proyek yang lebih detail dan menentukan waktu pengerjaan proyek.

b. Waktu (Time)

Merupakan lamanya waktu yang diperlukan untuk menyelesaikan sebuah proyek. Semakin lama suatu proyek dikerjakan, maka semakin besar biaya operasional proyek yang dibutuhkan.

c. Biaya (Cost)

Merupakan komponen biaya proyek. Komponen ini juga saling terkait dengan dua komponen sebelumnya (produk dan waktu) karena semakin besar lingkup proyek dan semakin lama waktu yang diperlukan untuk menyelesaikan proyek maka akan semakin besar biaya suatu proyek.

Idealnya, suatu proyek yang baik adalah proyek yang dapat selesai tepat waktu (time), sesuai dengan budget yang telah direncanakan sebelumnya (cost) dan lingkup pekerjaan yang 
disetujui (scope) sesuai dengan kualitas yang diharapkan atau ditentukan sebelumnya (quality).

Kerangka kerja (framework) memberikan strukur dasar untuk memahami manajemen proyek berdasarkan sembilan area pengetahuan manajemen proyek. Dimana stakeholders memiliki tujuan atau harapan yang dituangkan dalam sebuah proyek. Seorang Manajer Proyek akan memimpin dan mengelola proyek tersebut. Pengelolaan proyek meliputi kegiatan yang sesuai dengan area pengetahuan manajemen proyek yang menggunakan peralatan (tools), teknik dan metode terkait untuk mencapai tujuan yang diharapkan oleh stakeholder.

\section{3 e-commerce}

E-commerce didefinisikan sebagai penggunaan internet untuk memfasilitasi, melaksanakan, dan transaksi bisnis proses. Transaksi bisnis melibatkan pembeli dan penjual dan pertukaran barang atau jasa untuk uang.

E-Commerce atau Electronics Commerce merupakan sebuah metodologi bisnis modern, yang membahas kebutuhan organisasi bisnis, vendor dan pelanggan untuk mengurangi biaya dan meningkatkan kualitas barang dan jasa sekaligus meningkatkan kecepatan pengiriman. E-commerce mengacu pada pertukaran paperless informasi bisnis menggunakan cara berikut:

- Pertukaran Data Elektronik (EDI)

- Electronic Mail (e-mail)

- Electronic Bulletin Board

- Elektronic Fund Transfer (EFT)

- Teknologi lainnya berbasis yang berbasis jaringan

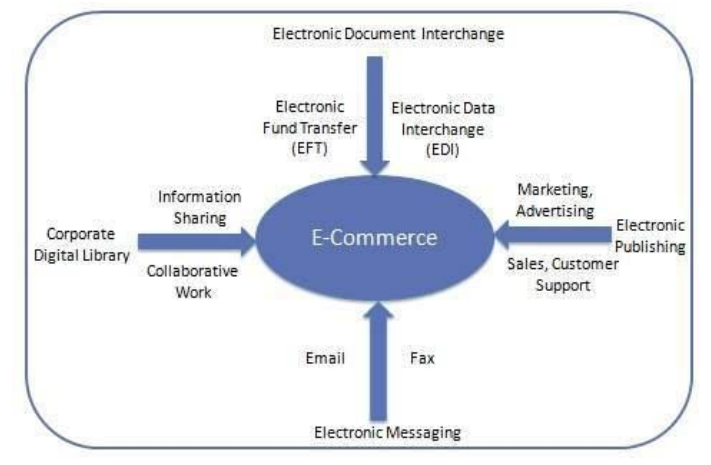

\subsubsection{Model Bisnis pada e-commerce}

- Business - to - Business (B2B)

B2B adalah aktivitas transaksi bisnis secara elektronik antara pel aku bisnis dengan pelaku bisnis lainnya.B2B berkaitan dengan permintaan dan pengiriman proposal bisnis.

- $\quad$ Business - to - Consumer (B2C)

B2C merupakan aktivitas e-business yang dilakukan produsen kepada konsumen dengan menggunakan media elektronik secara langsung.

- Consumer - to - Consumer (C2C)

C2C merupakan aktivitas bisnis (penjualan) yang dilakukan oleh individu (konsumen) kepada individu (konsumen) lainnya.

- Consumer - to - Business (C2B)

C2B merupakan model bisnis di mana konsumen (individu) menciptakan dan membentuk nilai akan suatu produk dan perusahaan menggunakan nilai ini.C2B melihat ide konsumen sebagai suatu input bagi produsen dalam melakukan produksi.

- Business - to - Government (B2G)

B2G merupakan turunan dari B2B dalam ilmu pemasaran dan dikenal sebagai pemasaran sektor publik yang mencakup pemasaran produk-produk dan jasa untuk instansi pemerintah.

- Government - to - Citizen (G2C)

G2C merupakan aplikasi pengembangan e-government dimana pemerintah menciptakan dan menerapkan berbagai portofolio Teknologi Informasi dengan tujuan untuk memperbaiki hubungan interaksi dengan masyarakat dan melakukan pelayanan bagi masyarakat.

\section{PENDEKATAN DALAM MANAJEMEN PROYEK}

\section{A. Tujuan Proyek}

Tujuan dari proyek ini adalah membangun sebuah jaringan komputer yang dapat 
memberikan kemudahan teknologi dan informasi yang berkaitan dengan kegiatan berbelanja bagi para konsumen Lovalates Departemen Store. Dengan demikian diharapkan dapat memberikan kemudahan bagi para konsumen dan keuntungan bagi perusahaan..

\section{B. Tahapan Pendekatan Proyek}

1. Analisis kebutuhan penggunaan komputer, hardware dan software yang akan diimplementasikan.

2. Perancangan arsitektur jaringan komputer.

3. Pengembangan sistem.

4. Ujicoba konektifitas jaringan komputer.

5. Mengembangkan estimasi biaya proyek untuk implementasi.

\section{HASIL DAN PEMBAHASAN}

\subsection{Inisiasi Proyek}

\section{A. Profil Perusahaan}

PT Lovalattes Indonesia adalah salah satu perusahaan ritel terkemuka di Indonesia yang menyediakan perlengkapan pakaian, aksesoris, produk-produk kecantikan dan rumah tangga dengan harga terjangkau. Perusahaan ini membuka gerai offlinenya yang bernama Lovalattes Departement Store. Lovalattes bermitra dengan pemasok pemasok terpercaya di Indonesia dan luar negeri untuk menyediakan kombinasi barang-barang fashion berkualitas tinggi yang dapat diterima oleh konsumen yang sadar akan nilai suatu produk. Gerai-gerai Lovalattes yang modern dan luas menyajikan pengalaman berbelanja dinamis dan inspiratif yang membuat konsumen datang kembali dan membantu menjadikan Lovalattes sebagai department store pilihan di kalangan kelas menengah Indonesia yang tumbuh pesat.

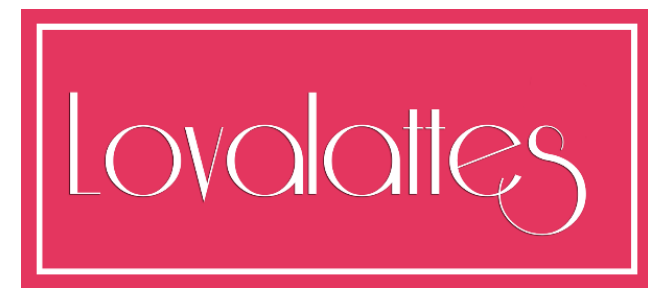

Logo Lovalattes Departemen Store

\subsubsection{Rancangan Usulan Sistem}

Alamat situs e-commerce yang akan digunakan oleh Lovalattes Dept Store adalah lovalattes.com. Sama seperti di gerai offline, barang-barang fashion yang disediakan berasal dari pemasok / supplier produk fashion kenamaan dari dalam negeri atapun luar negeri. Barang-barang yang dijual tersebut nantinya bisa dilihat oleh pengunjung website secara online (24 jam sehari). Proses utamanya adalah transaksi pembelian oleh konsumen. Langkah awalnya, calon pelanggan yang mengunjungi website dapat mendaftar melalui menu yang telah disediakan. Kemudian, calon pelanggan mengisi data diri sesuai formulir yang sudah disediakan. Setelah berhasil mendaftar, maka pelanggan harus login dahulu untuk melakukan proses pemesanan produk. Setelah berhasil login dan memesan produk, pelanggan dapat melihat pesanan, mengubah pesanan, menghapus pesanan, atau melanjutkan ke proses selanjutnya. Ada beberapa metode pembayaran yang ditawarkan diantaranya yaitu bayar di tempat, Kartu Kredit, ataupun transfer bank. Lovalattes juga menjalin kerja sama dengan bank BCA dan Mandiri dengan menyediakan layanan BCA Klikpay dan Mandiri ClickPay sebagai salah satu metode pembayaran yang disediakan.

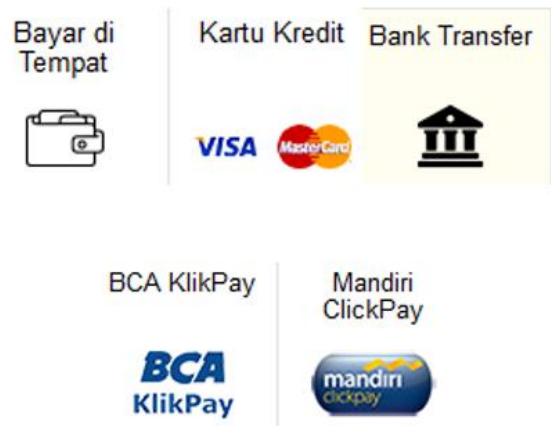

Pokok bahasan penulis terletak pada proses saat setelah pembeli melakukan pembayaran. Data-data pembeli tersimpan oleh server client. Metode Transfer antar bank merupakan pelayanan jasa bank dalam transfer dana dari satu account ke account lain baik dalam satu institusi bank maupun antar institusi bank lain. Semula jasa bank dengan memakai warkat (transfer secara fisik) kemudian beralih dengan menggunakan teknik elektronik. Pada dasarnya transaksi dengan menggunakan Electronic Funds Transfer berbeda dengan transaksi 
pembayaran secara konvensional yang dilakukan dengan menggunakan kertas (paper) maka dalam Electronic Funds Transfer transaksi pembayaran dilakukan menggunakan media elektronik yang mencakup transaksi Kartu Kredit, Automated Teller Machine (ATM) dan Transfer Dana. Jika pembeli memilih metode transfer bank, client server akan terkoneksi dengan server bank untuk memperoleh data-data pembeli. Lalu setelah pembeli melakukan pembayaran, server bank akan mengirimkan data ke server pusat berupa informasi tentang pembayaran yang telah dilakukan oleh pembeli.

Atau, jika pembeli menggunakan metode pembayaran dengan kartu kredit, Data nasabah kemudian mengalir ke jaringan (network) LAN yang dikelola oleh pihak ketiga, dalam hal ini PT Lovalattes. Aliran data kemudian masuk ke pusat data (data center) Bank X. Dari sini data kemudian diolah di dalam NAC (Network Access Control), Cardlink Mainframe dan MIP (Mastercard Interface Processor) /VAP (Visa Access Point). Setelah selesai data nasabah kemudian masuk ke network Visa/Master melalui gateway international. Dari jaringan Visa/Mastercard ini, data nasabah akan dipilah berdasarkan issuernya, apakah kartu tersebut kartu kredit Bank X, Citibank, Mandiri dan sebagainya. Kemudian proses data berulang (looping) dan apabila data nasabah valid dan outstanding kredit lancar atau mencukupi maka transaksi akan langsung diapproved oleh mesin EDC. Nasabah membawa pulang barang belanjaannya.

\section{B. Ruang Lingkup Proyek}

Ruang Lingkup proyek adalah sebagai berikut :

- Perangkat yang akan digunakan dalam proyek ini berupa Hardware, Software dan perangkat pendukung lainnya yang dibeli dan disewa

- Modul yang dikembangkan meliputi : konektifitas jaringan, arsitektr jaringan dan laporan-laporan yang diperlukan apabila ada penambahan maupun keluhan dari modul yang kami kembangkan

- Model jaringan yang digunakan menggunakan jaringan LAN, sehingga semua koneksi yang ada hanya dapat digunakan di dalam lingkungan perusahaan Lovalattes.

\section{Faktor Penentu Keberhasilan Proyek}

1. Teknologi

Teknologi merupakan bagian dari proyek yang mempunyai dampakbesar pada kesuksesan proyek

Teknologi yang digunakan manajemen atau tim proyek antara lain :

a) Mengukur kemajuan proyek

b) Mempunyai ide-ide umum dari teknologi yang dapat mewujudkan sesuatu yang diharapkan

c) Tidak menjadi halangan ketika langkah dan perkembangannya lambat

2. Organisasi

Faktor-faktor organisasional yang berdampak pada kelangsungan hidup proyek

Faktor-faktor organisasional yang dimaksud diantaranya adalah :

\section{a. Internal competition}

Untuk memberikan motivasi tim proyek dan juga sumber daya yang berkualitas

\section{b. Managemen support and the Company's market strategi}

Berperan sebagai penyedia sumber daya, pengarah pelaksanaan proyek dan fasilitator dalam mengimplementasikan tujuan organisasi

3. Kekuatan-kekuatan Pasar

Persaingan perusahaan di dalam pasar berpengaruh kuat pada kelangsungan proyek baru maupun proyek yang adakan datang

4. Perencanaan

Merupakan faktor penting dagi kegagalan dan kesuksesan proyek

Kegunaan :

a) mengurangi resiko dan meningkatkan kualitas

b) sebagai dasar perencanaan dan pengoranisasian yang lebih efektif dari pengalaman tim proyek

5. Tim Proyek 
Kemampuan tim dalam melaksanakan kinerja dalam sebuah tim yang akan memiliki komitmen dan spesifikasi sesuai dengan persyaratan yang diperlukan proyek

Tujuan :
a) Memberikan komitmen
b) Antusias
c) Melakukan koordinasi
d) Menyelesaikan konplik yang timbul

6. Faktor Ekonomi

Merupakan frekuensi perputaran investasi yang dapat menunjukkan kesusesan dan kegagalan sebuah proyek

Tujuan :

a) agar proyek mampu mengembalikan invertasi dengan cepat, sedang atau gagal

b) perusahaan membuat ukuran baku berkaitan dengan kondisi financial (pendapatan)

c) melakukan evaluasi setiap akhir proyek

7. Lain-lain

Faktor-faktor lain yang dapat berpengaruh terhadap kesuksesan dan kegagalan dalam sebuat proyek

\section{Contoh :}

a) peraturan pemerintah yang baru.

b) masalah-masalah yang berkaitan dengan hak paten kepemilikan

c) pengaruh lingkungan baru.

\subsection{Jadwal Proyek}

Jadwal Proyek

Pembangunan Jaringan Komputer Pada Perusahaan E-commerce

PT. Lovalattes Indonesia

\begin{tabular}{|c|c|c|c|c|}
\hline & & & -2016 & -2016 \\
\hline 1.1 & $\begin{array}{l}\text { Pengembangan } \\
\text { Proposal Proyek }\end{array}$ & 2 & $\begin{array}{c}01-01- \\
2016\end{array}$ & $\begin{array}{l}02-01 \\
-2016\end{array}$ \\
\hline 1.2 & $\begin{array}{l}\text { Persetujuan } \\
\text { Proposal Proyek }\end{array}$ & 1 & $\begin{array}{l}03-01 \\
-2016\end{array}$ & $\begin{array}{l}03-01 \\
-2016\end{array}$ \\
\hline 1.3 & $\begin{array}{l}\text { Pembentukan Tim } \\
\text { Proyek }\end{array}$ & 4 & $\begin{array}{l}04-01 \\
-2016\end{array}$ & $\begin{array}{l}07-01 \\
-2016\end{array}$ \\
\hline 2 & $\begin{array}{l}\text { Pembangunan } \\
\text { Arsitektur dan } \\
\text { Pengujian }\end{array}$ & 56 & $\begin{array}{l}08-01 \\
-2016\end{array}$ & $\begin{array}{l}03-03 \\
-2016\end{array}$ \\
\hline 2.1 & $\begin{array}{l}\text { Analisis Kebutuhan } \\
\text { Jaringan }\end{array}$ & 2 & $\begin{array}{l}08-01 \\
-2016\end{array}$ & $\begin{array}{l}09-01 \\
-2016\end{array}$ \\
\hline 2.2 & $\begin{array}{l}\text { Pembelian } \\
\text { Perangkat }\end{array}$ & 4 & $\begin{array}{l}10-01 \\
-2016\end{array}$ & $\begin{array}{l}13-01 \\
-2016\end{array}$ \\
\hline 2.3 & $\begin{array}{l}\text { Penerapan Instalasi } \\
\text { Jaringan Komputer }\end{array}$ & 30 & $\begin{array}{l}14-01 \\
-2016\end{array}$ & $\begin{array}{l}12-02 \\
-2016\end{array}$ \\
\hline 2.4 & $\begin{array}{l}\text { Penerapan Instalasi } \\
\text { Server }\end{array}$ & 4 & $\begin{array}{l}13-02 \\
-2016\end{array}$ & $\begin{array}{c}16-02 \\
-2016\end{array}$ \\
\hline 2.5 & $\begin{array}{l}\text { Penerapan Instalasi } \\
\text { OS pada PC }\end{array}$ & 4 & $\begin{array}{l}17-02 \\
-2016\end{array}$ & $\begin{array}{l}20-02 \\
-2016\end{array}$ \\
\hline 2.6 & $\begin{array}{l}\text { Konfigurasi } \\
\text { Jaringan (Router, } \\
\text { Switch, Server, dll) }\end{array}$ & 7 & $\begin{array}{l}21-02 \\
-2016\end{array}$ & $\begin{array}{l}27-02 \\
-2016\end{array}$ \\
\hline 2.7 & $\begin{array}{l}\text { Penerapan Hak } \\
\text { akses Jaringan }\end{array}$ & 3 & $\begin{array}{l}28-02 \\
-2016\end{array}$ & $\begin{array}{l}01-03 \\
-2016\end{array}$ \\
\hline 2.8 & $\begin{array}{l}\text { Review Koreksi } \\
\text { Akhir }\end{array}$ & 2 & $\begin{array}{l}02-03 \\
-2016\end{array}$ & $\begin{array}{l}03-03 \\
-2016\end{array}$ \\
\hline 3 & Implementasi & 7 & $\begin{array}{l}04-03 \\
-2016\end{array}$ & $\begin{array}{l}10-03 \\
-2016\end{array}$ \\
\hline 3.1 & Testing Jaringan & 4 & $\begin{array}{l}04-03 \\
-2016\end{array}$ & $\begin{array}{l}07-03 \\
-2016\end{array}$ \\
\hline 3.2 & Training Operator & 3 & $\begin{array}{l}08-03 \\
-2016\end{array}$ & $\begin{array}{l}10-03 \\
-2016\end{array}$ \\
\hline & $\begin{array}{l}\text { Total Pelaksanaan } \\
\text { Proyek }\end{array}$ & 70 & $\begin{array}{l}01-01 \\
-2016\end{array}$ & $\begin{array}{l}10-03 \\
-2016\end{array}$ \\
\hline
\end{tabular}


4.3 Rencana Anggaran Belanja Proyek

Rencana Manajemen Biaya Proyek

Pembangunan Jaringan Komputer Pada Perusahaan E-commerce

PT. Lovalattes Indonesia

\begin{tabular}{|c|c|c|c|c|}
\hline $\begin{array}{l}\text { WB } \\
\text { S }\end{array}$ & $\begin{array}{l}\text { Gugus Tugas } \\
\text { Proyek }\end{array}$ & $\begin{array}{c}\text { Dura } \\
\text { si } \\
(\text { Hari } \\
\text { ) }\end{array}$ & $\begin{array}{l}\text { Fee / } \\
\text { Hari } \\
\text { (Rp.) }\end{array}$ & $\begin{array}{l}\text { Total } \\
\text { fee } \\
\text { (Rp.) }\end{array}$ \\
\hline 1 & $\begin{array}{l}\text { Persiapan } \\
\text { Proyek }\end{array}$ & 7 & $\begin{array}{l}100.0 \\
00\end{array}$ & 700.000 \\
\hline 1.1 & $\begin{array}{l}\text { Pengembangan } \\
\text { Proposal Proyek }\end{array}$ & 2 & $\begin{array}{l}100.0 \\
00\end{array}$ & 200.000 \\
\hline 1.2 & $\begin{array}{l}\text { Persetujuan } \\
\text { Proposal Proyek }\end{array}$ & 1 & $\begin{array}{l}100.0 \\
00\end{array}$ & 100.000 \\
\hline 1.3 & $\begin{array}{l}\text { Pembentukan } \\
\text { Tim Proyek }\end{array}$ & 4 & $\begin{array}{l}100.0 \\
00\end{array}$ & 400.000 \\
\hline 2 & $\begin{array}{l}\text { Pembangunan } \\
\text { Arsitektur dan } \\
\text { Pengujian }\end{array}$ & 56 & $\begin{array}{l}75.00 \\
0\end{array}$ & \begin{tabular}{|l}
4.200 .0 \\
00
\end{tabular} \\
\hline 2.1 & $\begin{array}{l}\text { Analisis } \\
\text { Kebutuhan } \\
\text { Jaringan }\end{array}$ & 2 & $\begin{array}{l}75.00 \\
0\end{array}$ & 150.000 \\
\hline 2.2 & $\begin{array}{l}\text { Pembelian } \\
\text { Perangkat }\end{array}$ & 4 & $\begin{array}{l}75.00 \\
0\end{array}$ & 300.000 \\
\hline 2.3 & $\begin{array}{l}\text { Penerapan } \\
\text { Instalasi } \\
\text { Jaringan } \\
\text { Komputer }\end{array}$ & 30 & $\begin{array}{l}75.00 \\
0\end{array}$ & \begin{tabular}{|l}
2.250 .0 \\
00
\end{tabular} \\
\hline 2.4 & $\begin{array}{l}\text { Penerapan } \\
\text { Instalasi Server }\end{array}$ & 4 & $\begin{array}{l}75.00 \\
0\end{array}$ & 300.000 \\
\hline 2.5 & $\begin{array}{l}\text { Penerapan } \\
\text { Instalasi OS } \\
\text { pada PC }\end{array}$ & 4 & $\begin{array}{l}75.00 \\
0\end{array}$ & 300.000 \\
\hline
\end{tabular}

\begin{tabular}{|c|c|c|c|c|}
\hline 2.6 & $\begin{array}{l}\text { Konfigurasi } \\
\text { Jaringan } \\
\text { (Router, Switch, } \\
\text { Server, dll) }\end{array}$ & 7 & $\begin{array}{l}75.00 \\
0\end{array}$ & 525.000 \\
\hline 2.7 & $\begin{array}{l}\text { Penerapan Hak } \\
\text { akses Jaringan }\end{array}$ & 3 & $\begin{array}{l}75.00 \\
0\end{array}$ & 225.000 \\
\hline 2.8 & $\begin{array}{l}\text { Review Koreksi } \\
\text { Akhir }\end{array}$ & 2 & $\begin{array}{l}75.00 \\
0\end{array}$ & 150.000 \\
\hline 3 & Implementasi & 7 & $\begin{array}{l}45.00 \\
0\end{array}$ & 315.000 \\
\hline 3.1 & Testing Jaringan & 4 & $\begin{array}{l}45.00 \\
0\end{array}$ & 180.000 \\
\hline 3.2 & $\begin{array}{l}\text { Training } \\
\text { Operator }\end{array}$ & 3 & $\begin{array}{l}45.00 \\
0\end{array}$ & 135.000 \\
\hline 4 & Perencanaan & 70 & \multicolumn{2}{|c|}{ 5.215.000,- } \\
\hline 5 & Hardware & 4 & \multicolumn{2}{|c|}{ 174.408.400,- } \\
\hline 5.1 & $\begin{array}{l}\text { Dedicated } \\
\text { Server }\end{array}$ & 1 & \multicolumn{2}{|c|}{$113,900,000$} \\
\hline 5.2 & Router & 1 & \multicolumn{2}{|c|}{$29,276,500$} \\
\hline 5.3 & Switch & 1 & \multicolumn{2}{|c|}{$21,199,900$} \\
\hline 5.4 & Firewall & 1 & \multicolumn{2}{|c|}{$10,032,000$} \\
\hline 6 & Bandwith & 3 & \multicolumn{2}{|c|}{ 93.398.450,- } \\
\hline 6.1 & FO 1 & 1 & \multicolumn{2}{|c|}{38.530 .450} \\
\hline 6.2 & FO 1500 meter & 1 & \multicolumn{2}{|c|}{19.868 .000} \\
\hline 6.3 & Dedicated FO & 1 & \multicolumn{2}{|c|}{35.000 .000} \\
\hline 7 & Database & 1 & \multicolumn{2}{|c|}{135.601 .432} \\
\hline 7.1 & MS 2014 & 1 & \multicolumn{2}{|c|}{135.601 .432} \\
\hline
\end{tabular}




\begin{tabular}{|l|l|c|c|}
\hline & $\begin{array}{l}\text { Perencanaan } \\
\text { Total }\end{array}$ & 78 & 408.623 .282 \\
\hline
\end{tabular}

\subsection{Analisis SDM}

\section{- Struktur Organisasi Proyek}

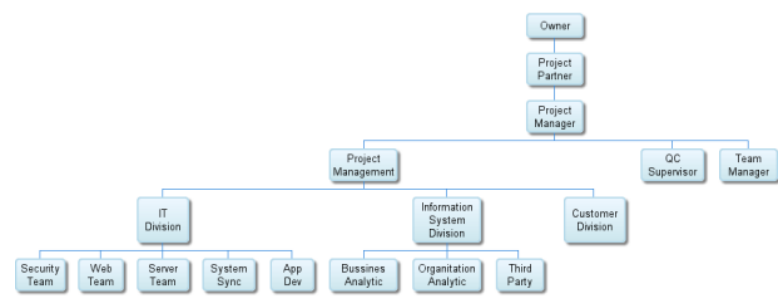

Owner adalah seorang manajemen puncak (beserta anggota tim jika perlu), yang diserahkan tugas khusus oleh perusahaan sebagai penanggung jawab proyek sistem informasi. Paling tidak salah seorang anggota direksi harus berada dalam tim ini untuk mencegah hambatan-hambatan berarti dalam pelaksanaan proyek.

Secara prinsip, Direktur Utama atau Presiden Direkturlah yang menjadi Owner. Owner inilah yang kemudian akan mencari rekanan atau seorang Project Partner dari sebuah perusahaan konsultan yang memang sudah ahli di bidang perencanaan dan pengembangan sistem informasi yang dimaksud.

Project Partner Sebagai pemegang jabatan tertinggi dari sebuah perusahaan konsultan, bertanggung jawab untuk mempersiapkan tim khusus dari multi disiplin sebagai anggota proyek yang akan dijalankan. Project Partner bertanggung jawab secara langsung kepada Owner yang menyewanya. Bagi seorang Project Partner, bagian yang terpenting dalam melakukan seleksi dan memilih anggota tim adalah memilih Project Manager yang memiliki kompetensi dan keahlian khusus dalam menangani proyek sistem informasi ini.

Project Manager Selain harus memiliki pengalaman dan pengetahuan dalam menangani proyek-proyek sejenis, harus pula memiliki kemampuan leadership yang baik dan tingkat aksetibilitas yang tinggi di mata perusahaan dan para anggota tim yang direkrut, disamping kebiasaan bekerja keras dan kondisi kesehatan yang prima. Dapat dikatakan bahwa Project Manager merupakan kunci kesuksesan proyek terkait karena ditangannyalah tanggung jawab tertinggi pelaksanaan proyek secara operasional berada. Dalam merencanakan, memonitor, dan mengontrol proyek sehari-hari.

Project Management terdiri dari para praktisi yang biasa menangani aktivitas-aktivitas komersial berbasis proyek. Fungsinya untuk membantu Project Manager dalam mengontrol pemakaian sumber daya-sumber daya terbatas dalam proyek (keuangan, SDM, waktu, kertas, alat-alat tulis, dan lain sebagainya) agar sesuai dengan anggaran yang telah direncanakan sebelumnya.Mereka pulalah yang harus memberitahu Project Manager jika ada hal-hal yang dapat mengakibatkan tertundanya proyek dan memberikan usulan-usulan atau rekomendasi terhadap kendala tersebut.

Quality Control Supervisor terdiri dari tim yang mengawasi agar pelaksanaan proyek dapat selalu terjamin kualitasnya sesuai dengan standar mutu yang ada (standar lokal perusahaan konsultan yang bersangkutan atau standar internasional seperti ISO). Fokus dari tim QC lebih pada kualitas dari outputoutput yang dihasilkan oleh proyek ini, seperti laporan, rekomendasi, desain, perangkat lunak, perangkat keras, dan lain sebagainya.

Team Manager terdiri dari sekumpulan team leader dari beberapa divisi yang ada, tugas mereka untuk melakukan koordinasi secara langsung maupun secara tidak langsung kepada hirarki diatas mereka maupun dibawahnya. Team Manager bertanggungjawab penuh atas alur koordinasi dan alur komunikasi antar setiap divisi yang dikelolanya.

Information Technology yang merupakan jawaban atas kebutuhan sistem informasi yang telah didefinisikan (supply oriented). Semua rencana strategis yang telah disusun oleh kedua tim sebelumnya pada akhirnya harus diimplementasikan secara teknis. Dilihat dari karakteristik pekerjaannya, biasanya ada empat jenis pengembangan teknologi yang dilakukan: -Membangun infrastruktur jaringan teknologi informasi, biasanya berupa proyekproyek perencananaan dan pembangunan jaringan komunikasi seperti LAN (Local Area Network), WAN (Wide Area Network), Intranet, Internet, dan Extranet;

-Membeli paket software atau hardware yang siap pakai di pasaran dan 
mengimplementasikannya dalam perusahaan (package implementation);

-Membuat software sendiri berdasarkan kebutuhan dan desain yang dibuat oleh tim yang dibentuk secara khusus oleh perusahaan (custom development atau in-house development)

-Melakukan dua atau ketiga hal diatas dan mengintegrasikannya satu sama lain (system integration).

Information System akan memfokuskan diri pada jenis-jenis informasi apa yang dibutuhkan oleh perusahaan dalam menjalankan bisnis sehari-hari (demand oriented) dan hal-hal lain yang berkaitan dengannya, seperti :

-Ahli strategi sistem informasi merupakan pakar utama yang dibutuhkan tim untuk mendefinisikan jenis-jenis informasi yang harus dihasilkan dengan segala karakteristiknya bagi perusahaan;

-Pakar manajemen resiko akan melihat resiko bisnis yang mungkin dihadapi seandainya terjadi kesalahan atau hal-hal lain dalam sistem informasi yang dibangun;

-Ahli contingency planning akan mempersiapkan prosedur yang harus dilakukan perusahaan jika ada gangguan teknis sistem yang dapat menggangu aktivitas perusahaan;

-Pakar manajemen proyek akan mempersiapkan strategi dalam menjalankan portfolio proyek sistem informasi yang beragam berdasarkan skala prioritas dan keterbatasan sumber daya;

-Spesialisasi suports dan services yang akan mengajukan usulan bagaimana memelihara sistem informasi setelah proyek selesai dilaksanakan (pasca implementasi), termasuk di dalamnya kemungkinan outsourcing, usulan pembangunan infrastruktur khusus (call center, help desk, dan lain-lain), sampai dengan prosedur-prosedur yang harus dilakukan.

\subsection{Arsitektur Jaringan}

\section{A. Teknologi}

\section{- Hardware}

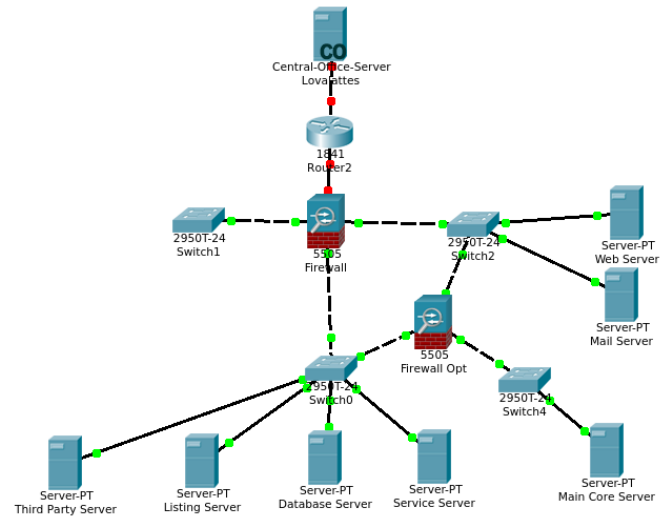

Dedicated Server adalah layanan penyewaan server yang diletakkan di data center FiberNet, perangkat server disediakan dan dikelola oleh FiberNet. Layanan yang ditawarkan adalah bersifat Unmanaged Service yang artinya dukungan teknis diberikan sampai pada jaringan dan hardware. Spec Xeon E5 606 Octa Core - 16 GB RAM - 10 x 2TB - 1 Public IP. HP ProLiant DL380G9-689 (Dual Xeon)

Server :Mail Server, Database Server, Backup Server, Listing Server, Web Server, Proxy Server.

RouterCISCO Router Enterprise [1921SEC/K9] 2 Integrated 10/100/1000 Ethernet, 2 Enhanced High-Speed WAN Interface Card, Doublewide EHWIC slots, 512DRAM, IP Sec + SSL. Rp 29,276,500

Switch NETGEAR ProSafe Switch [GS752TP] 48-port 10/100/1000 BaseT (48ports PoE), 4 SFP Dedicated, PoE Budget 384 Watts (8-port POE Plus), Web-management. Network Protocol and Standards Compatibility IEEE 802.1D Spanning Tree (STP), IEEE 802.1s Multiple Spanning Tree (MSTP), IEEE 802.1w Rapid Spanning Tree(RSTP), IEEE 802.1X Radius network access control, IEEE 802.3 at (PoE Plus).

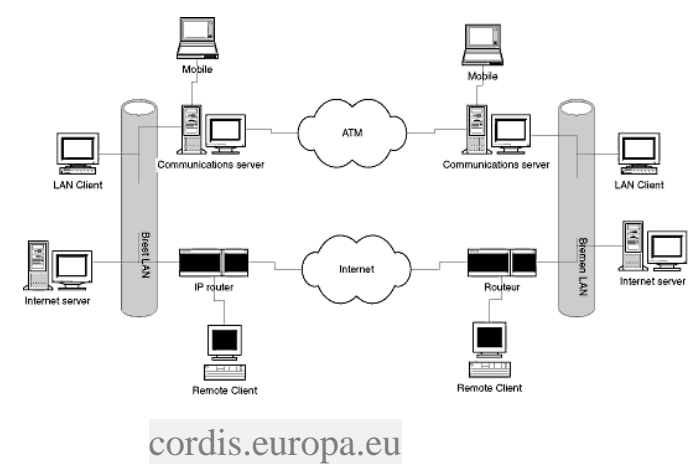




\section{- Software}

\section{a) Bandwith}

Fiber Optic FO Cable 4 Core Outdoor Multimode, Netviel - Media Converter, 10/100FX-10/100TX, Micronet 2 Unit - ST Connector, Amp 8 Pcs - FO Patch Cord ST to SC, Amp 2 Pcs - FO Wallmount Rack 4 ST Coupler, Amp 2 Unit - Buffer Tubing Kits, Amp 8 Pcs FO Cable Terminating 8 Node.

\section{FO Fiber Optik 500 Mtr}

Biznet Fiber Network Broadband Internet service from 10 - 200 Mbps. Safe, fast and stable connection. The connection uses RJ-45 cable, can be directly connected to a broadband router, firewall, proxy or an existing LAN switch. Large bandwidth capacity for local and international access. Metronet 4, Speed 50 Mbps Dedicated, 1 Dynamic IP Public.

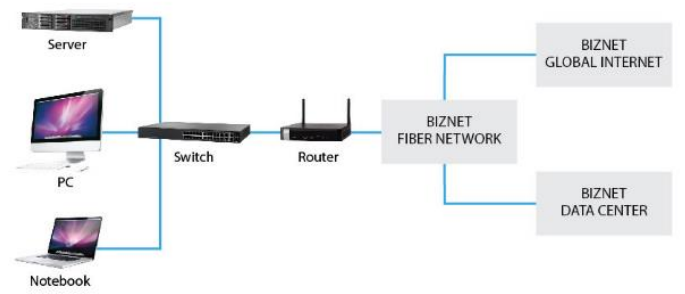

b) Firewall

NETGEAR ProSAFE VPN Firewall [SRX5308]

\begin{tabular}{|c|c|}
\hline $\begin{array}{l}\text { Network } \\
\text { Connection }\end{array}$ & $\begin{array}{l}\bullet 4 \text { x 10/100/1000 WAN } \\
\bullet 4 \text { x 10/100/1000 LAN }\end{array}$ \\
\hline \multirow[t]{2}{*}{ Data Rates } & $\begin{array}{l}\text { - LAN-to-WAN Throughput : } \\
924 \mathrm{Mbps}\end{array}$ \\
\hline & $\begin{array}{l}\text { - Psec VPN (3DES) } \\
\text { Throughput : } 180 \text { Mbps } \\
\text {-SSL VPN Throughput : } 21 \\
\text { Mbps }\end{array}$ \\
\hline Encryption & $\begin{array}{l}\text { DES, } 3 \text { DES, } \\
\text { AES(ECB, } \quad \text { CBC, } \\
\text { CNTR)128, } 256 \text { bit }\end{array}$ \\
\hline $\begin{array}{l}\text { Standards } \\
\text { Protocol }\end{array}$ & $\begin{array}{l}\text { DHCP, Static IP Assignment, } \\
\text { PPPoE, PPTP }\end{array}$ \\
\hline
\end{tabular}

\begin{tabular}{|c|c|}
\hline Other & $\begin{array}{l}\text { - Firewall Features } \\
\text { Stateful Packet Inspection } \\
\text { (SPI) : Port/Service } \\
\text { Blocking, Denial-of-service } \\
\text { (DoS) Prevention, Stealth } \\
\text { Mode, Block TCP Flood, } \\
\text { Block UDP Flood, } \\
\text { WAN/LAN Ping Response } \\
\text { Control } \\
\text { Firewall Functions : Port } \\
\text { Range Forwarding, Port } \\
\text { Triggering, DNS proxy, } \\
\text { MAC Address } \\
\text { Cloning/spoofing, NTP } \\
\text { Support, UPnP, Auto- } \\
\text { Uplink on Switch Ports, L3 } \\
\text { Quality of Service } \\
\text { (QoS),LAN-to-WAN and } \\
\text { WAN-to-LAN(ToS), } \\
\text { Bandwidth Profiling } \\
\text { Content Filtering : Web } \\
\text { Components (Proxy, Java, } \\
\text { ActiveX, Cookies), Web } \\
\text { Keyword Blocking, Trusted } \\
\text { Domains Authentication for } \\
\text { User Active Directory, } \\
\text { VPN : WIKID, } \\
\text { LDAP, Radius, DT Domain, Local } \\
\text { MIAS, NT } \\
\text { User Database }\end{array}$ \\
\hline
\end{tabular}

c) Aplikasi

Common Gateway Interface atau disingkat CGI adalah suatu standar untuk menghubungkan berbagai program aplikasi kehalaman web.

CGI mirip sebuah program komputer yang menjadi perantara antara standar HTML yang menjadikan tampilan web dengan program lain, seperti basis data (database).Hasil yang diperoleh dari proses pencarian dikirimkan kembali ke halaman web untuk ditampilkan dalam format HTML.

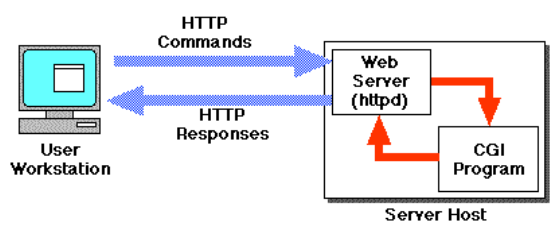

Java Digunakan untuk membuat interaksi antar konten yang ada pada website dan pada client.

JSP (Java Server Pages) Digunakan untuk melakukan pengembangan situs 
lebih lanjut dengan menggabungkan kombinasi dari HTTP, JSP, Javascript secara dinamis agar client dapat melakukan interaksi dengan server dengan lebih cepat.

Java Script Digunakan untuk mengendalikan objek pada halaman web dan menangani interaksi pada browser.

OS Ubuntu Server Ubuntu Server 14.04.3 LTS

\section{d) Database}

MICROSOFT SQL Server 2014

Business Intelligence [D2M-00667]

\section{PENUTUP}

A. Kesimpulan

\section{Arsitektur E-Commerce}

Kerangka kerja perencanaan konseptual dimana aplikasi bisnis dan teknologi informasi didesain sebagai arsitektur terpadu dari sistem perusahaan yang mendukung inisiatif bisnis strategis dan proses bisnis lintas fungsi. Arsitektur dasar dari aplikasi web lovalattes.com adalah arsitektur client server. Artinya pemrosesan aplikasi ini dijalankan melibatkan kedua sisi yakni sisi mesin server pusat dan sisi client.

Didalam membangun infrastruktur ecommerce dipergunakan kerangka arsitektur yang terdiri dari berbagai building block. Entity-entiti blok ini seperti permainan anak-anak yaitu lego, yang dapat dengan mudah di copot dan dipasang sesuka hati sesuai dengan kebutuhan dan keinginan, untuk mendirikan sebuah arsitektur sesuai keinginan.

Arsitektur ini dibangun oleh berbagai building blok yang didalamnya dapat dikonfigurasikan sesuai dengan kebutuhan perusahaan. Komponen-komponen tersebut antara lain : Order management server, product configuration server, dynamic content server, commerce transaction server, dan secured acces server. Masingmasing komponen ini secara fleksibel dapat dengan mudah dibongkar pasang sesuai dengan kebutuhan spesifik perusahaan. Berikut merupakan penjelasan secara singkat mengenai fungsi beberapa komponen yang berada didalam arsitektur sistem e-commerce.

1. Order Management ServerSistem ini memiliki fungsi utama untuk menangani masalah pemesanan produk atau jasa sampai dengan proses pengirimannya kepada konsumen. Setelah perusahaan melakukan validasi terhadap pemesanan produk yang dilakukan oleh calon pembeli, sistem ini secara otomatis mengirimkan perintah pengadaan barang kebagian pemasok yang biasanya telah memiliki sistem informasinya sendiri. Untuk memberitahukan konsumen bahwa pesanannya telah diproses dan dalam status tertentu, dipergunakan sebuah metode khusus yang dinamakan event notification agent

2. Product Configuration Server

Pada prinsipnya sistem ini dibangun untuk mempermudah konsumen dalam menentukan konfigurasi produk yang diinginkan, tentu saja dengan catatan bahwa produk yang ditawarkan dapat di tentukan spesifikasinya sesuai dengan keinginan spesifik konsumen. Biasanya cara kerja sistem ini mempergunakan konsep ruled based engine dimana berdasarkan sejumlah peraturan tertentu, konsumen dapat melakukan tailor mede terhadap konfigurasi dan spesifikasi produk akhir yang diinginkan.

\section{Dynamic Content Server}

Komponen ini merupakan jantung dari informasi perusahaan dimana secara dinamis dan kontinyu melakukan pengelolaan dan update terhadap infromasi halaman HTML yang dapat ddengan mudah diakses oleh konsumen. DIkatakan dinamis karena perusahaan dapat dengan mudah merubah berbagai inforamsi properties dari produk yang ditawarkan dengan mudah secara otomatis perubahan tersebut akan dicatat oleh halaman HTML terkait sehingga konsumen dapat melihat informasi yang terbaru. 
4. Commerce Transaction Server

Transaks E-commerce biasanya melibatkan berbagai pihak, mulai dari proses pemesanan sampai dengan pembayaran dan distribusi produk yang dibeli. Terhadap beragam proses tersebut, sejumlah server atau sistem lain harus bekerjasama berdasarkan aturan dan scenario yang disepakati. Sistem ini bertugas untuk mengelola keperluan tersebut, agar proses transaksi yang melibatkan sejumlah server dapat berjalan dengan efektif.

5. Secured Access Server

Sesuai dengan namanya sistem ini bertujuan untuk menjaga agar transaksi yang berjalan dapat terjamin kemanannya seperti keamanan proses pembayaran,keamanan proses pengiriman dokumen, keamanan proses verifikasi, keamanan proses autientifikasi dan lainnya

\section{DAFTAR PUSTAKA}

- https://www.academia.edu/6807525/M embangun_Situs_E-Commerce

- https://www.techopedia.com/definition /16955/network-infrastructure

- http://oz.stern.nyu.edu/fall99/pdf/netw orking.pdf

- Tati Mardiana. 2011. Perencanaan manajemen proyek sistem informasi akuntansi keuangan daerah menggunakan framework ITPOSMO, AMIK BSI, Bandung.

- William H. DeLone \& Ephraim R. McLean. 2014. Measuring eCommerce Success: Applying the DeLone \& McLean Information Systems Success Model, ROUTLEDGE, U.S

- Darren R. Davis, dkk. 2012. Medium and System for Location-BasedCommerce For Mobile Communication Device, Microsoft Corporation, U.S

- https://www.academia.edu/9357052/C ONTOH_PROPOSAL_MANAJEME N_PROYEK http://www.slideshare.net/martinaoctav iaadventina/laporan-proposalperancangan-jaringan-pada-sebuahhotel. 